\title{
ANÁLISIS DE LAS PARTES, APODERADOS Y LÍMITES DE LA AGENCIA OFICIOSA EN LA CONCILIACIÓN EXTRAJUDICIAL EN COLOMBIA*
}

\section{Analysis of parties, representatives, and limits of the officious intermeddler in the extrajudicial conciliation in Colombia}

\author{
Abel Meza-Godoy** \\ Milton Arrieta-López ${ }^{* * *}$ \\ Laura Patricia Carrasquilla-Díaz ${ }^{* * *}$
}

Recepción: 27 de enero de 2021. Aceptación: 12 de agosto de 2021

DOI: http://dx.doi.org/10.21017/Rev.Repub.2021.v31.a113

\section{RESUMEN}

La Constitución Política de 1991 permitió en su artículo 116 que los particulares pudiesen ser investidos de jurisdicción como en los casos de árbitros y conciliadores, a pesar de que esta investidura quedó limitada a ciertos aspectos de temporalidad y de poder que poseen los jueces de la República de Colombia.

* Artículo inédito. Producto del proyecto de investigación titulado: Perspectivas de la relación de la sociedad con el Estado en el marco de la política, el derecho y la educación. Inscrito en el Grupo de Investigación Derecho, Política y Sociedad categorizado por Minciencias y avalado por la Universidad de la Costa.

** Conciliador extrajudicial diplomado y registrado. Máster en Derecho del Comercio. Máster en Dirección y Administración de Empresas. Especialista en Derecho Privado Económico. Especialista en Derecho Societario. Abogado. Investigador júnior categorizado por Minciencias. Barranquilla, Colombia. ORCID: 0000-0002-4347-6143. Dirección electrónica: abelrmg@yahoo.es

*** Máster en Derechos Humanos, Democracia y Globalización. Máster en Dirección y Administración de Empresas. Especialista en Derecho Privado Económico. Abogado. Investigador asociado categorizado por Minciencias. Coordinador editorial de la revista indexada Jurídicas CUC. Director del Centro de Investigaciones Sociojurídicas y Políticas. Docente e investigador del Departamento de Derecho y Ciencias Políticas de la Universidad de la Costa. Barranquilla, Colombia. ORCID: 0000-0002-3437-5025. Dirección electrónica institucional: marrieta7@cuc.edu.co Dirección electrónica personal: miltonarrieta@yahoo.com

****Máster en Derecho Privado Patrimonial. Especialista en Derecho Comercial. Abogada. Investigadora asociada categorizada por Minciencias. Docente e investigadora del Departamento de Derecho y Ciencias Políticas de la Universidad de la Costa. Barranquilla, Colombia. ORCID: 0000-0001-8873- 3855. Dirección electrónica institucional: lcarrasq2@cuc.edu.co Dirección electrónica personal: laura.carrasquilla@gmail.com 
En ese sentido, el conciliador en ejercicio de su jurisdicción temporal puede examinar la comparecencia de las partes y establecer si estas se encuentran facultadas para disponer del derecho controvertido. El objeto del presente trabajo es determinar, mediante la metodología del análisis crítico, la revisión bibliográfica y documental, si el agente oficioso puede reunir los requisitos de parte en la audiencia de conciliación. Se llega a la conclusión de que por ausencia de atribución legal y en virtud de su naturaleza jurídica el agente oficioso no puede ser considerado como parte en la conciliación extrajudicial.

Palabras clave: agente oficioso, partes, conciliación, apoderados, MASC.

\begin{abstract}
The Political Constitution of 1991 in its article 116 states that individuals could be endowed with jurisdiction to perform as arbitrators and conciliators, despite the fact that this endowment was limited to certain aspects of time and power held by Colombian judges. In this sense, it shows how the conciliator in the exercise of his jurisdiction may examine how the parties appear and whether they are entitled to dispose of the disputed right. The purpose of this paper is to determine, through the methodology of documentary review, bibliography and critical analysis if the officious intermeddler can meet the requirements to represent a party at the settlement hearing. The study concludes that due to the absence of legal attribution and by virtue of the legal nature of the officious intermeddler, this one cannot be considered as a party in the extrajudicial conciliation.
\end{abstract}

Keywords: officious intermeddler, parties, conciliation, representatives, ADR.

\title{
I. INTRODUCCIÓN
}

La Constitución Política colombiana de 1991 en su artículo 228 elevó a rango constitucional la administración de justicia especificándola como una función pública autónoma e independiente. Además, acorde al artículo 229 el acceso a la justicia se predica para todas las personas, aún sin la representación de un abogado ante cualquier jurisdicción, sea esta municipal, de circuito e incluso en los tribunales y altas cortes. Mas aún, la misma Carta en el artículo 116 permitió que los particulares y ciertas autoridades administrativas pudiesen asumir investidura de jurisdicción, como en el caso de los superintendentes, conciliadores y árbitros.

Conviene subrayar la prominencia de las atribuciones jurisdiccionales otorgadas a los particulares y, que para efectos del presente artículo, se destacan las referidas al conciliador, en tanto que este no posee los mismos poderes 
generales de un juez de la República, como la decisión, la coerción y la investigación (salvo en la conciliación judicial), sino que queda limitado a ejercer la jurisdicción como un tercero mediador que procura que la litis sea solucionada entre las mismas partes intervinientes, quedando restringido a guiar, mediar o proponer fórmulas de arreglo, pero con el poder de convalidación de los acuerdos que nazcan de la voluntad de los legitimados en el conflicto.

Si se revisa la exposición de motivos de la Ley 640 de 2001, se explica que el objeto de la ley pretendió robustecer a la justicia alternativa que se desarrolló en la Ley 446 de 1998 como forma de arreglo pacífico de las disputas (González, 1999), es decir, como un método de solución de litigios, que en todo caso procura una mejor justicia que la que prevén las instancias ordinarias de justicia, en tanto que las mismas partes son las que elaboran la solución del conflicto, no así el juez de la República en el ejercicio de su poder de decisión a través de una providencia judicial, la cual de ninguna forma será discutida o puesta a disposición de las partes previamente para ser por ellos aprobada y que ante un escenario de desacuerdo lo que procederá es la impetración de los recursos de ley, con el fin de que el mismo funcionario judicial u otro de mayor jerarquía sean quienes decidan la litis, independiente de la intención o el querer de ambas partes en conflicto. En efecto, la conciliación no solo procura una justicia superior, sino que ayuda a restablecer la relación entre las partes; al respecto conviene subrayar que la solución de la controversia proviene de las mismas partes en litigio, lo cual evita que un juez de conocimiento, en su calidad de tercero imparcial, declare a un vencedor y un vencido; no obstante, resulta preponderante la intervención oportuna de un conciliador ético y capaz de brindar fórmulas de arreglo calificadas pero que respete la decisión libre y voluntaria de las partes respecto a la resolución de la controversia (Arrieta-López, 2019; Hernández, 2007).

Sobre este punto la Ley 446 de 1998 manifiesta en su artículo 65 que son conciliables los asuntos susceptibles de transacción, desistimiento y aquellos que determine la ley, lo cual no dista de lo desarrollado en el artículo 19 de la Ley 640 de 2001, que aduce que se podrán conciliar todos los asuntos susceptibles de conciliación, transacción y desistimiento ante los conciliadores del Centro de Conciliación, los servidores públicos facultados para conciliar a los que se refiere la mencionada ley, y los notarios. A los anteriores se pueden sumar las facultades de los Consultorios Jurídicos conforme a los artículos 5 y 11 de la Ley 640 de 2001, que se encuentran limitados para conocer asuntos cuya cuantía exceda los cuarenta (40) salarios mínimos legales vigentes (SMLV), lo cual es concordante con lo determinado en el Código General del Proceso en su artículo 25, respecto de la estipulación de la mínima cuantía (Ley 1564, 2012); esto teniendo en cuenta que un salario mínimo legal vigente en Colombia para el año 2021 asciende a la suma de novecientos ocho mil quinientos veintiséis pesos en moneda legal colombiana (\$908.526.00), lo cual corresponde a 
doscientos sesenta dólares con noventa y nueve centavos (US\$260.99), según la tasa oficial de cambio para el 8 de enero de 2021.

Por ese mismo fin, el artículo primero de la ley de la conciliación (Ley 640, 2001) en el parágrafo segundo respecto a la comparecencia obligó a que sean las mismas partes las que accedan a la audiencia, exceptuando el caso en que una, varias o todas las partes se encuentren fuera del circuito judicial del Centro de Conciliación o entidad autorizada para realizarla, caso en el cual se podrá nombrar a un apoderado judicial que los represente, siempre y cuando conste en el acto de apoderamiento las facultades especiales para conciliar.

La conciliación, además de ser una fórmula de solución pacífica de controversias, es un mecanismo de solución autocompositivo de acuerdo a la Ley 640 de 2001, y también es un requisito de procedibilidad (Grueso-Hinestroza y AntónRubio, 2011; Devis, 2017), lo que implica que deberá intentarse previamente a la iniciación del proceso judicial, conforme a sus artículos 35 y 38, para acceder a los procesos declarativos, con excepción de los siguientes casos:

1. Los de expropiación o divisorios.

2. Cuando bajo la gravedad del juramento, que se entenderá prestado con la presentación de la demanda, se manifieste que se ignora el domicilio, el lugar de habitación y el lugar de trabajo del demandado, o que este se encuentra ausente y no se conoce su paradero.

3. Cuando en el proceso de que se trate, y se quiera solicitar el decreto y la práctica de medidas cautelares, caso en el cual se podrá acudir directamente a la jurisdicción. De lo contrario, tendrá que intentarse la conciliación extrajudicial en derecho como requisito de procedibilidad, de conformidad con lo previsto en la presente ley.

4. Procesos con pretensiones ejecutivas o liquidatorias.

5. En la conciliación de familia cuando existen circunstancias de violencia intrafamiliar. Esta causal la expuso la sentencia C-1195 de 2001, de la Honorable Corte Constitucional, amparados en el concepto de protección a la víctima, con el fin de no obligarla a encontrarse nuevamente con su agresor.

6. En los demás que determine la ley, como por ejemplo la existente en el proceso de restitución de tenencia.

Igualmente, la ley de la conciliación trajo consecuencias procesales ante el no agotamiento del requisito de procedibilidad, como: 
a. Multa: Cuando la conciliación extrajudicial en derecho sea requisito de procedibilidad y se instaure la demanda judicial, sin perjuicio de lo previsto en los artículos 22 y 29 de la Ley 640 de 2001, el juez impondrá multa a la parte que no haya justificado su inasistencia a la audiencia. Esta multa se impondrá hasta por valor de dos (2) salarios mínimos legales mensuales vigentes en favor del Consejo Superior de la Judicatura (Ley 640, 2001, art. 35).

b. Inadmisión y rechazo de la demanda: La ausencia del requisito de procedibilidad de que trata la Ley 640 de 2001 dará lugar al rechazo plano de la demanda, sin dejar de lado la causal de inadmisión que derivaría en el posterior rechazo de la demanda que consta en el artículo 90, numeral $7 .^{\circ}$, del Código General del Proceso, cuando esta no se subsane dentro de los cinco días siguientes a que se notifique la providencia que así lo sustente.

En este punto consideramos que al ser el Código General del Proceso una norma posterior a la Ley 640 de 2001, lo que aplica es la causal de inadmisión con el fin de que el demandante subsane su yerro en caso de que este provenga del olvido o negligencia del accionante al momento de presentar la demanda.

c. Indicio grave: Salvo en materia laboral, policiva y de familia, si las partes o alguna de ellas no comparece a la audiencia de conciliación a la que fue citada y no justifica su inasistencia dentro de los tres (3) días siguientes, su conducta podrá ser entendida como indicio grave en contra de sus pretensiones o de sus excepciones de mérito en un eventual proceso judicial que verse sobre los mismos hechos (Ley 640, 2001, art. 22).

El aspecto de prerrequisito de procedibilidad ha sido objeto de críticas al establecerse la desnaturalización que sufre la conciliación al convertirla en una etapa del proceso judicial con consecuencias por la inasistencia, y no como un mecanismo voluntario para que las partes puedan resolver sus conflictos (Meza et al., 2018; Ahumada, 2011). Sobre lo anterior Maldonado y Montaña expresan lo siguiente: «El hecho es que, en la práctica, los MASC no han sido el respiro que se esperaba; e incluso podría decirse que se han desnaturalizado, como en el caso de la conciliación prejudicial, que se aparta de toda voluntariedad de las partes para convertirse en una etapa más del proceso» (Maldonado y Montaña, 2017, p. 123). Según Arrieta y Rojas:

La mayoría de los jueces han entendido que el referido artículo estableció la conciliación previa al proceso con carácter obligatorio, constituyendo como un nuevo presupuesto de la demanda el acompañar al líbelo el certificado que contiene la conciliación parcial o bien, que exprese que no hubo conciliación (Arrieta y Rojas, 2002, p. 65). 
Desde otro punto de vista, consideramos que, aún en su obligatoriedad, permanece la intención de propender por el arreglo pacífico y autocompositivo del conflicto, lo cual puede ser promovido por el tercero conciliador (Azula, 2016), a pesar de que con justa razón se piense que lo coercitivo de su celebración puede menguar la voluntad del arreglo.

No está demás resaltar que la conciliación se vuelve relevante en el acceso a la administración de justicia ordinaria, cuando en el proceso verbal o en el proceso verbal sumario se le otorga un espacio en las audiencias (Toscano, 2015; Arboleda et al., 2018), sin soslayar que en virtud de la Ley 640 del 2001, artículo 43, en cualquier etapa del proceso podrán los sujetos procesales requerir de común acuerdo la celebración de la audiencia con el fin de dirimir sus diferencias y el juez tendrá el deber de aprobarla siempre que esta no sea contraria a derecho, sin importar si corresponde a un acuerdo total o parcial de las pretensiones; por otro lado y como dato no menor, el juez puede de oficio citar a audiencia si dilucida un ánimo conciliatorio entre las partes.

Ahora bien, es importante preguntarnos qué ocurre cuando terceros pretenden intervenir o actuar en nombre de una de las partes, aún en calidad de abogados carentes de poder, bajo el pretexto de la institución jurídica del agente oficioso. En ese orden de ideas, el objeto del artículo consiste, a partir de la conceptualización de las partes y apoderados en la conciliación en civil y de la naturaleza jurídica de la agencia oficiosa, resolver la pregunta planteada sobre la imposibilidad para los terceros de actuar como agentes oficiosos y, por ende, firmar el acta del acuerdo de conciliación.

\section{ESTRATEGIA METODOLÓGICA}

La presente investigación es de corte dogmático-jurídico puesto que se fundamentó en el estudio teórico y analítico de las leyes 640 de 2001 y 1564 de 2012, complementado con una revisión sistemática de documentos cuyas categorías temáticas estuvieron relacionadas con el marco jurídico y doctrinal de las partes, los apoderados y el cuasicontrato de la agencia oficiosa en el contexto de la conciliación extrajudicial, para lo cual se aplicaron tres criterios de selección para la pesquisa de información: pertinencia, de acuerdo a la importancia de los objetivos planteados; profundidad: se revisaron las fuentes disponibles; y actualidad, en cuanto a las investigaciones, hallazgos y avances más novedosos.

La investigación se asentó en el paradigma cualitativo por cuanto asumió la elaboración de un análisis reflexivo de la realidad jurídica implícita en la Ley 640 de 2001 que se constituye en el objeto del presente estudio. 


\section{DESARROLLO}

\section{Las partes en la conciliación en civil}

Desde la Ley 640 de 2001 en su artículo primero, también en la jurisprudencia y la doctrina se ha reiterado la importancia de la comparecencia de las partes en litigio al procedimiento conciliatorio, en tanto que las fórmulas definitivas de arreglo nacen de la voluntad consciente de ellas, para dirimir el conflicto que entre las partes existe; por ello la sentencia C-1195 de 2001 consideró desde su acepción procedimental que «la conciliación es un mecanismo de resolución de conflictos a través del cual, dos o más personas gestionan por sí mismas la solución de sus diferencias, con la ayuda de un tercero neutral y calificado, denominado conciliador», y desde el punto de vista sustancial y su materialización la entendió como «un acta que consigna el acuerdo al que llegan las partes, certificado por el conciliado» (Sentencia C-1195. 2001).

Por otro lado, la Ley 446 de 1998 hace alusión al concepto de conciliación señalando que esta es «un mecanismo de resolución de conflictos a través del cual, dos o más personas gestionan por sí mismas la solución de sus diferencias, con la ayuda de un tercero neutral y calificado, denominado conciliador». Así mismo la ley antes mencionada resaltó igualmente la importancia de las partes al manifestar que «es un mecanismo de resolución de conflictos a través del cual, dos o más personas gestionan por sí mismas la solución de sus diferencias» (art. 64).

Si traemos a colación el concepto de parte desde lo doctrinal, Devis Echandía (2017) lo definió de la siguiente manera:

«Por consiguiente, el concepto procesal de partes es puramente formal, es decir, en materia civil, laboral y contencioso administrativa, aquel que demanda en nombre propio o en cuyo nombre se demanda la sentencia o el mandamiento ejecutivo, mediante el proceso; quien es demandado directamente o por conducto de su representante, y quien interviene luego de modo permanente y no transitorio o incidental; esta intervención permanente puede ser como litisconsortes, como simples coadyuvantes, como terceristas o ad excludendum, y como persona jurídica. Pero excepcionalmente es también parte el sustituido en el proceso, sin que actúe en él ni siquiera por representante, pues el sustituto procesal obra en nombre propio y por interés personal» (p. 286).

Ramiro Bejarano (2019) afirma que la conciliación es un procedimiento en el cual un tercero imparcial llamado conciliador procura avenir a las partes, bien para que prescindan de un litigio o para que solucionen una controversia. El conciliador, a pesar de la indebida referencia que hace el artículo 116 de la 
Constitución, no es un administrador de justicia, no ejerce la potestad jurisdiccional, pues en ningún caso dicta el derecho.

El autor Paz explica sobre el concepto de parte que es quien interviene en un proceso con una pretensión, con la cual se reclama un derecho; a este sujeto se le conoce como demandante, y al que se le incoa la pretensión es el demandado; en sentido estricto, esas son las partes del proceso (Paz, 2015).

En ese sentido la capacidad para ser parte del proceso, que deviene del acceso a la justicia, es protegida en la Constitución Política a través de su artículo 229, según el cual «se garantiza el derecho de toda persona para acceder a la administración de justicia. La ley indicará en qué casos podrá hacerlo sin la representación de abogado»; y legalmente, según la Ley 270 de 1996, en su artículo segundo que señala: «el Estado garantiza el acceso de todos los asociados a la administración de justicia. Será de su cargo el amparo de pobreza y el servicio de defensoría pública. En cada municipio habrá como mínimo un defensor público»; queda no solo atribuida por ende a las personas ya sean naturales o jurídicas (Cuesta-Cuesta, 2015; Díaz, 2020), sino también a la apenas concebidas, a los patrimonios autónomos y a los grupos de personas, tal como lo menciona la Ley 1564 de 2012, en su artículo 53.

Es menester entonces, empezar a distinguir entre la institución jurídica de parte procesal y la de goce de ese derecho, lo cual estará atribuido por ley a ciertas personas que ejercerán directa o indirectamente los actos de acción y contradicción en cada uno de los procesos.

Así, entonces, la persona que disponga de sus derechos podrá asistir directamente al proceso civil, como el mayor de edad, mientras que los demás deberán comparecer a través de sus representantes, como es el caso del padre de familia en la solicitud de alimentos de un menor, o la persona jurídica por su representante legal, y los patrimonios autónomos por el apoderado o representante de la sociedad fiduciaria que actúa como su vocera, resaltando en este punto que la Ley 1564 de 2012 permitió que las personas jurídicas también compareciesen mediante de sus representantes legales para cuestiones judiciales, o apoderados generales debidamente inscritos (Arrieta y Meza, 2019). Por último, el Código General del Proceso en su artículo 54 ratifica la comparecencia del liquidador cuando la persona jurídica figure en estado de liquidación, y en asuntos de familia para los concebidos por quienes serían sus representantes, si ya hubiesen nacido.

Siendo la conciliación en civil una forma autocompositiva de solución de conflictos, inicialmente el papel del conciliador dentro de la revisión previa de los documentos contentivos de la solicitud correspondería a identificar si, confor- 
me a los hechos, los comparecientes poseen capacidad de ejercicio y de goce del derecho (Tamez et al., 2018), para que lo acordado en audiencia sea firmado por aquellos que puedan desistir, renunciar, transar, conciliar el conflicto allegado y en ese sentido citar en lo posible aquellas partes que considere, deben comparecer el día de la audiencia (Mojica, 2015). Este punto hay que distinguirlo de la solicitud de audiencia de conciliación, la cual puede hacerse directamente por el convocante o por su apoderado (Concepto nro. 12919, 2004), siendo verdaderamente relevante como parte para el conciliador quien comparece a la audiencia, independiente de si fue el poderdante o apoderado quien suscribió el documento de la solicitud (Peña-Sandoval, 2017); es por esto que para entender el concepto de parte en la conciliación, no necesariamente debemos adentrarnos a la solicitud de conciliación, en la cual existe un convocante y un convocado, sino que será parte aquel que es estimado como tal, ya sea por la solicitud de conciliación o porque el conciliador lo citó amparado en las atribuciones de la Ley 640 de 2001, artículo 8. ${ }^{\circ}$, para la audiencia.

Ahora bien, con la expedición del Código General del Proceso se desató la discusión sobre quiénes poseen la calidad de parte y de terceros, distinción que en la conciliación civil deberá ser observada para la consolidación y la pertinencia de los presentes en audiencia. Así, entonces, el citado código incluyó como partes a los liticonsortes facultativos (Art. 60), los liticonsortes necesarios (Art. 61), los litisconsortes cuasinecesarios (Art. 62), al interviniente excluyente (Art. 63), al llamado en garantía (Art. 64), al poseedor o tenedor (Art.67), los sucesores procesales (Art.68) y los intervinientes para incidentes, y solo incluyó como terceros al coadyuvante (Art. 71) y al llamado de oficio (Art. 72).

Serán entonces, según el caso, las partes enunciadas en el Código General del Proceso las llamadas a comparecer en la audiencia de conciliación con el fin de ventilar sus diferencias y procurar a través del tercero conciliador las posibles fórmulas de arreglo, que de concretarse serán plasmadas en el acta de acuerdo.

En este punto cabe concluir que el conciliador, una vez conozca la solicitud, primero revisará si los intervinientes tienen capacidad para ser parte; consiguientemente, si todas las partes según la causa u objeto de la convocatoria a la audiencia fueron invitadas, y en ese sentido el conciliador deberá citar a aquellas que no fueron convocadas (Ley 640, 2001, art. 8). Sin embargo, queda el vacío normativo de determinar si se podrá prescindir de convocarlos cuando el conciliador no lo vea pertinente o conexo a la causa de la solicitud, a lo cual consideramos que si bien el conciliador posee investidura transitoria de jurisdicción, la carencia de poder de decisión lo limita para abstenerse de citar a un convocado en audiencia, así no tenga legitimación, por cuanto solo el juez de la República podrá decidir mediante 
providencia motivada la pertinencia o legitimación del sujeto procesal, sea o no un litisconsorte o un tercero sin incidencia en la litis. En tales circunstancias podrán presentarse a título de ejemplo las siguientes eventualidades: cuando el deudor cite a los acreedores de una prestación, y el conciliador encuentre que falte uno de ellos, siendo necesaria su presencia para ventilar sus diferencias, deberá propender por la constitución del litisconsorcio necesario, y por consiguiente enviar la citación al acreedor faltante; si se cita a un deudor solidario quedará en la potestad del conciliador, sin ser obligatorio, citar a los demás deudores a la diligencia para constituir un litisconsorcio cuasinecesario, al tener el citado la potestad de poder firmar o negociar el acuerdo de conciliación, ya sea total o parcialmente, sin necesidad de los demás deudores; en la responsabilidad civil extracontractual por accidente de tránsito a diferentes víctimas, se abstendrá de citar a las demás víctimas cuando la solicitud de conciliación solo sea allegada por una de ellas, al comprender un litisconsorte facultativo, ya que las acciones judiciales podrán ser instauradas por cada una por separado e incluso la sentencia que se dicte en un posible proceso puede ser de distinto resultado para cada uno; para la citación de un poseedor o tenedor, puede ocurrir que en la audiencia de conciliación el citado manifieste que no tiene esa calidad, por tal motivo y en concordancia con el artículo 67 del Código General del Proceso y el artículo 8. ${ }^{\circ}$ de la Ley 640 de 2001, consideramos que el conciliador podrá suspender la audiencia y fijar nueva fecha con el fin de que en su continuación se presente quien aduce el citado con esa calidad, claro está si se allega una dirección a efectos de invitar a ese tercero a la diligencia, en caso contrario deberá continuarla y finalizarla con el acuerdo o con la constancia de no conciliación.

Se torna preponderante la figura del llamado en garantía que, siendo garante de la responsabilidad patrimonial por una sentencia adversa, puede ser citado por vía de acción en la demanda o en el término de traslado como ejercicio de la contradicción. Es de recordar que el llamado en garantía es considerado parte en el Código General del Proceso, como un litisconsorte facultativo o voluntario, que en el evento de vislumbrarlo el conciliador en la solicitud, y al no ser citado por el convocante, quedará a potestad del mismo estudiar la necesidad de ser comprendido o informado para asistir a la audiencia de conciliación; igualmente ocurre cuando en una solicitud se cita a una persona jurídica de la cual se ventila una fusión, escisión, o se encuentre un adquirente de los derechos litigiosos, a los cuales podrá citar el conciliador como sucesores procesales con interés legítimo en la conciliación.

Estas intervenciones del conciliador dentro del trámite previo de la conciliación o en la diligencia, suspendiéndola a efectos de fijar nueva fecha para continuar en presencia de los comparecientes interesados, se encontrarían 
fundamentadas en el artículo 8, numerales $1 .^{\circ}$ y $2 .^{\circ}$, de la Ley 640 de 2001, en los que no solo tienen la facultad expresa de citar a las partes conforme a la ley, sino también de invitar a aquellas que a su criterio deban concurrir a la audiencia.

No es menos importante resaltar que la audiencia de conciliación no es un escenario de pruebas, por lo que no podrá justificarse la presencia de terceros a efectos de dejar constancias de declaraciones, documentos $\mathrm{u}$ otro medio de probatorio que pretendan dar convencimiento de la razón de lo expresado por las partes, ya que entraría en un escenario de mutación jurídica la audiencia de conciliación al convertirse en una audiencia de instrucción, cuando su único fin es el encontrar posibles fórmulas de arreglo y no que la figura del conciliador a través de su investidura transitoria dicte providencias sustentadas en las pruebas aportadas.

\section{Representación judicial de los intervinientes en el proceso de conciliación}

Ahora bien, la mera capacidad de goce y ejercicio no garantiza que las partes en el proceso civil ejerzan una correcta defensa de sus intereses; por consiguiente, se hace necesario que comparezcan a través de sus apoderados (Ley 1564, 2012, arts. 53 y 73) con el fin de garantizar la defensa técnica en las actuaciones procesales. Por tal motivo, el derecho de postulación a través de apoderado busca proteger el buen ejercicio del derecho de la defensa, tal como lo dispone el artículo 29 de la Constitución Política. Este requisito no es equiparable totalmente para la audiencia de conciliación, ya que si bien el abogado puede asistir a la audiencia (Ley 1564, 2012, art. 1), la presencia de la parte es la obligatoria para efectos de comenzar y desarrollar la audiencia, al punto del establecimiento de sanciones como la de indicio grave en contra de quien no justifique su inasistencia (Ley 640, 2001, art. 22) o la sanción de multa que nos trae el parágrafo único del artículo 35 de la Ley 640 de 2001.

Y es que no se puede confundir el ejercicio de la abogacía mediante un apoderado con la parte en sí misma, ya que la parte corresponde al sujeto procesal vinculado con la causa y el objeto del litigio mientras que el apoderado es un profesional que lo representa en virtud de un mandato, y que en últimas podrá ser removido en cualquier momento. La anterior afirmación es causa de confusión para ciertos apoderados que asisten a las audiencias de conciliación, en tanto que consideran que el mandato otorgado por su cliente es suficiente para asistir y dar continuidad a la audiencia de conciliación, o ejercer como parte misma en la audiencia, sin recordar la obligatoriedad de la presencia de las partes como sujetos procesales vinculados al asunto discutido a la audiencia, lo cual es expreso en la Ley 640 de 2001, salvo excepción que contiene la misma ley. 


\section{Los apoderados generales}

Para efectos de la conciliación extrajudicial en derecho o en equidad, si bien se exige la presencia de las partes (Castro-Herrera y Jaramillo, 2018; Salazar y Cabello-Tijerina, 2020), consideramos como una de las excepciones a la norma que se pueda hacer extensiva la comparecencia a los apoderados generales para asuntos judiciales de las personas jurídicas, por el mandato expreso de la Ley 1564 de 2012, que en el artículo 54 permitió la comparecencia del proceso a través de estos mandatarios debidamente inscritos; en este punto y a manera de ejemplo, el conciliador deberá hacer revisión de los certificados de existencia y representación legal de las sociedades, cuando una de las partes se presente con estas atribuciones, no solo para dilucidar su inscripción sino también para verificar que esa inscripción posea la atribución de conciliar.

Por otro lado, podrá un apoderado judicial abogado comparecer a nombre de la persona jurídica o natural, cuando el domicilio de este se encuentre fuera del circuito judicial del lugar de la audiencia.

Finalmente, no está de más recalcar que en todo caso los apoderados generales deberán ser reconocidos mediante escritura pública (Ley 1564, 2012, art. 74).

\section{Los apoderados especiales}

Los apoderados especiales, los cuales se encuentran facultados para la actuación en particular, podrán ser constituidos mediante escritura pública o documento privado. En ese sentido, podrán acompañar a la parte en la audiencia o comparecer en nombre de ella cuando el domicilio de esta se encuentre fuera del circuito judicial del lugar donde se celebrará la audiencia.

No obstante, consideramos que el poder especial deberá ser aportado en documento escrito en el evento de la falta de comparecencia de la parte que representa y que esta parte se encuentre fuera del circuito judicial del lugar donde se celebra la audiencia; en consecuencia, cuando comparece, como soporte jurídico y acompañante de la parte de la audiencia, el poder podrá presentarse por escrito o ser reconocido $u$ otorgado en la misma audiencia de conciliación por el mandante al momento de iniciar la diligencia, y así se deberá dejar constancia en el acta.

\section{Facultades expresas del apoderado en la audiencia de conciliación}

Conforme a la Ley 1564 de 2012, los apoderados poseen facultades implícitas que no necesitan ser redactadas de manera expresa en el poder, como las de sustituir (art. 75); solicitar medidas cautelares extraprocesales, pruebas 
extraprocesales y demás actos preparatorios del proceso; solicitar medidas cautelares; interponer recursos ordinarios, de casación y de anulación; cobrar ejecutivamente las condenas; prestar juramento estimatorio, y confesar (art. 77).

Empero, el artículo 77 de la Ley 1564 de 2012 prohíbe la realización de actos reservados a la parte misma, como el de recibir, allanarse o disponer del derecho de litigio, salvo en la audiencia inicial del proceso verbal, en la cual si alguna de las partes no comparece, sin perjuicio de las consecuencias probatorias por su inasistencia, la audiencia se llevará a cabo con su apoderado, quien tendrá facultad para confesar, conciliar, transigir, desistir y, en general, para disponer del derecho en litigio.

La Ley 640 de 2001, exigió en el artículo 1. ${ }^{\circ}$, parágrafo segundo, la facultad expresa de conciliar para efectos de comparecer a la audiencia de conciliación cuando el domicilio de la parte que representa no se encuentra dentro del circuito judicial del lugar donde se celebra la diligencia, hecho que no se supone necesario cuando el apoderado participa como soporte jurídico de la parte asistente en la audiencia, ya que el consentimiento de lo acordado lo otorgará la firma de la parte y no la del abogado.

\section{La agencia oficiosa o gestión de negocios ajenos}

Tamayo definió la agencia oficiosa de la siguiente manera: «hay agencia oficiosa o gestión de negocios ajenos cuando una persona, el agente oficioso o gestor realiza un acto en interés de otra persona llamada dueño del negocio o interesado en forma espontánea, sin haber recibido mandato» (Tamayo, 2004, p. 296).

Díaz (2008), en relación con la Agencia Oficiosa, manifestó: «La Corte Suprema de Justicia, como máximo Tribunal de la Jurisdicción Ordinaria en nuestro País, se ha encargado de explicar que la agencia oficiosa no solo tiene ocurrencia cuando el mandatario en la ejecución de su encargo, se ve precisado a gestionar sin cláusula especial que lo autorice, sino se extiende a toda hipótesis en que una persona, sin mandato, asume de forma espontánea y voluntaria la ejecución de actos por cuenta del provecho del patrimonio de otra persona y con el ánimo de obligar, entregándole derroteros bastante claros a la institución» (Díaz, 2008).

Si nos remitimos al artículo 2304 del Código Civil, una de las características relevantes de la agencia oficiosa es la carencia de mandato de quien comparece como agente de otro; dicho de otra manera, carece de la existencia de un contrato previo entre las partes $\mathrm{y}$, por ende, de la voluntad del interesado; tal 
circunstancia desemboca en que su fuente, en materia de obligaciones, se encuadra en los cuasicontratos. Por otro lado, esta gestión deberá generar una verdadera utilidad al tercero y no un perjuicio para que se configure este tipo de cuasicontrato. Ahora bien, desde el punto de vista procesal, la carencia de mandato se mantiene; no obstante, deberán tenerse en cuenta los términos de la ratificación para que verdaderamente surja efecto.

\section{La agencia oficiosa procesal}

El Código General del Proceso reguló en su artículo 57 lo referente a la agencia oficiosa procesal, dando la oportunidad de demandar o contestar la demanda a nombre de una persona de la cual no se tiene poder, aunque se exige la ratificación, la cual deberá realizarse dentro de los treinta días siguientes al auto admisorio de la demanda o dentro de los 30 días siguientes al vencimiento del término del traslado para contestar la demanda cuando actuó en esa calidad. Conviene subrayar que la agencia oficiosa procesal cumplirá su fin una vez sea ratificada; de lo contrario, su proceder será inocuo.

\section{La agencia oficiosa en la conciliación prejudicial en civil}

No es menor la problemática que ocasionalmente se presenta en audiencias de conciliación cuando apoderados o particulares asisten aduciendo que actúan como agentes oficiosos de un tercero; lo anterior a pesar del parágrafo segundo del artículo 1 . $^{\circ}$ de la Ley 640 de 2001, que manifiesta que «las partes deberán asistir a la audiencia de conciliación y podrán hacerlo junto con su apoderado», lo cual constituye la dificultad por resolver.

En este punto consideramos necesario comprender lo que exige la Ley 640 de 2001 respecto de la comparecencia de las partes:

1. Exige la presencia de la parte convocante o convocada en la audiencia (art. 1, par. 2).

2. La parte puede presentarse en la audiencia acompañada de apoderado (art. 1, par. 2).

3. Cuando la audiencia es fuera del circuito judicial, podrá comparecer el apoderado con facultades para conciliar con el fin de representar a la parte en la audiencia (art. 1, par. 2).

4. La no comparecencia de las partes da lugar a indicio grave en contra de las excepciones o de las pretensiones e imposición de multa hasta en dos salarios mínimos mensuales (arts. 22 y 35). 
Al hablar de la parte en lo que respecta a la Ley 640 de 2001, indiscutiblemente tenemos que apoyarnos en el Código General del Proceso con el fin de comprender quiénes se encuentran facultados como sujetos de derecho procesal, y si como sujetos de derecho procesal poseen esa capacidad de goce, tal como lo menciona el artículo 54 y subsiguientes de la Ley 1564 de 2012. Por otro lado, debemos descartar la posibilidad de que quien actúe conforme a los hechos de la solicitud, sea un tercero, sin capacidad o facultar de transar, desistir, conciliar, renunciar o en fin de disponer de los derechos en litigio y por último el completar el litisconsorcio que se considere necesario a efectos de que no pierda efectos el acta de audiencia en el evento de un posible acuerdo.

Para el caso del agente oficioso, es necesario recordar en primer lugar que la fuente de obligaciones de la cual proviene esta figura jurídica es diferente de la que origina la existencia del contrato de mandato y, por ende, del apoderado judicial (abogado) facultado para la audiencia. En otras palabras, mientras el mandato proviene de una fuente de tipo contractual, el agente oficioso posee su origen en el cuasicontrato. Igualmente, al ejercer la actuación en nombre del otro sin mandato previo, el agente oficioso se comprende como una persona totalmente diferente a la parte, independiente de que quiera buscarle un provecho o utilidad a la persona por la cual actúa; por consiguiente, no tendrá facultad de disponer de los derechos discutidos en el asunto. Por otro lado, si nos apegamos al concepto de agente oficioso procesal, si bien la Ley 640 de 2001 preceptúa un procedimiento para la instalación de la audiencia y posterior registro, incluido dentro del límite de temporalidad de tres meses de investidura de jurisdicción del conciliador, este no regula en sus títulos o capítulos la oportunidad de comparecencia de agentes oficiosos o de su ratificación posterior como sí lo hace la Ley 1564 de 2012 en su artículo 57 para la demanda y contestación, obligándolos a que sean ratificados expresamente por quienes están actuando para la acción o para la excepción. Como consecuencia de lo anterior, si la norma prohíbe la presencia del apoderado sin la parte sujeto de derecho, cuando la audiencia se celebre dentro del circuito judicial del lugar de la audiencia, menos entonces podrá ser permitida la presencia de agentes oficiosos que actúen en nombre del tercero aún sin conocimiento del representado, y sin facultades para disponer de lo controvertido.

\section{CONCLUSIONES}

Se concluye fundamentalmente que el conciliador, para efectos de establecer la comparecencia de los intervinientes en la audiencia de conciliación, deberá integrar o tener como parte en la respectiva audiencia a aquellas personas naturales o jurídicas que son reconocidas en la Ley 1564 de 2012 como parte procesal, en razón a la causa estudiada en la convocatoria, por cuanto son ellas 
las que poseen la disposición de los derechos en litigio y por ende la capacidad para realizar un acuerdo conciliatorio.

Por otra parte, la naturaleza jurídica del agente oficioso implícita en sus elementos cuasicontractuales implica la carencia de un poder otorgado por la parte convocante o convocada ; por ende, se encuentra privado de la facultad de conciliar que expresamente establece la ley para firmar cualquier acuerdo de conciliación, sumado lo anterior a las limitantes que poseen los abogados, quienes no son considerados parte y que solo pueden ser acompañantes o asesores jurídicos, excepto cuando el domicilio del poderdante se encuentre fuera del circuito judicial del lugar de celebración de la audiencia.

El agente oficioso no puede ser parte en la audiencia de conciliación, ni podrá ampararse en las disposiciones del Código General del Proceso para fundamentar el reconocimiento de su actuar en las audiencias, precisamente por carecer de mandato, facultades, y no menos importante, de atribuciones amparadas en disposiciones legales que avalen su actuar en audiencias de conciliación. Se adiciona a la conclusión central lo siguiente:

- La Ley 640 de 2001 es clara al exigir la comparecencia de las partes en conflicto al procedimiento conciliatorio.

- El apoderado general para asuntos judiciales debidamente inscrito en los certificados de existencia y representación legal podrá asistir al procedimiento conciliatorio para representar a la persona jurídica, y en todo caso también deberá tener facultades de conciliar para tal efecto.

- El conciliador podrá revisar en qué calidad actúan el convocante y el convocado, y desde su análisis podrá citar a la audiencia a aquellas personas que considere necesarias para dejar con asidero suficiente el acta de la audiencia con los acuerdos totales o parciales contenidos en ella.

- El agente oficioso, al no ser parte, no podrá actuar en la audiencia de conciliación en nombre de otro, y en el evento de hacerlo, el conciliador entenderá que la parte no ha comparecido y podrá en ese sentido dejar las constancias de inasistencia dando lugar a las sanciones que la misma ley impone.

\section{REFERENCIAS}

Ahumada, M. (2011). La conciliación: un medio de justicia restaurativa; análisis y reflexiones de su implementación en el delito de inasistencia alimentaria en Co- 
lombia. Revista de la Facultad de Derecho y Ciencias Políticas, 41(114), 11-40. http:/ / www.scielo.org.co/scielo.php?script=sci_arttext\&pid=S0120-388620 11000100001\&lng=en\&tlng $=$.

Arboleda, A., Ramírez, C., Mancipe, G. Garcés, L. y Arboleda, S. (2018). La conciliación virtual extrajudicial en Derecho; reflexiones frente a la ética. Justicia, 24(34), 372-384.. https://doi.org/10.17081/just.23.34.289

Arrieta-López, M. (2019). De la democracia a la Aretecracia: origen, evolución y universalización. Utopía y Praxis Latinoamericana, 24, 115-132. https:/ / produccion cientificaluz.org/index.php/utopia/article/view/29689

Arrieta, M. y Rojas, A. (2002). Análisis de las garantías del proceso de alimentos y su eficacia dentro del proceso. [Tesis de pregrado] Facultad de Derecho. Universidad del Norte.

Arrieta, M. y Meza, A. (2019). Efectividad de la función de concreción de la obligación alimentaria de los defensores de familia en la ciudad de Barranquilla entre los años 2015 y 2017. Revista Jurídicas, 16(2), 147-165. https://doi.org/10.17151/ jurid.2019.16.2.10

Azula Camacho, J. (2016). Manual de Derecho Procesal, tomo Nro. 1, Bogotá, Editorial Temis.

Bejarano Guzmán, R. (2019). Procesos Declarativos, Arbitrales y Ejecutivos, Bogotá, Editorial Temis.

Castro-Herrera, F. y Jaramillo-Marín, J. (2018). La justicia en equidad y las violencias contra las mujeres en Colombia. Revista de Derecho, 31(2), 115-133. https:/ / doi.org/ 10.4067/S0718-09502018000200115

Constitución Política de la República de Colombia de 1991. (1991, 20 de julio). Gaceta Constitucional de 20 de julio de 1991. http:/ / www.secretariasenado.gov.co/senado/basedoc/constitucion_politica_1991.html

Cuesta-Cuesta, D. M. (2015). La conciliación en el ordenamiento jurídico colombiano. Una nueva forma de enseñar Derecho, Bogotá, Ediciones Universidad Cooperativa de Colombia. http:/ / hdl.handle.net/20.500.12494/10352

Devis Echandía, H. (2017). Teoría General del Proceso. III. Edición. Bogotá, Editorial Temis.

Díaz, J. C. (2008). El agente oficioso. Temas Socio-Jurídicos, 26(55). https:// revistas.unab.edu.co/index.php/sociojuridico/article/view/975 
Díaz, J. (2020). Reflexiones sobre los principios de celeridad, imparcialidad y eficiencia en el Código General del Proceso. Jurídicas CUC, 16(1), 407-444. https:/ / doi.org/ 10.17981/juridcuc.16.1.2020.18

González, R. (1999). Exposición de motivos Ley 640 de 2001, Secretaría General del Senado de la Republica de Colombia. https:/ / www.alcaldiabogota.gov.co/sisjur/ normas/Norma1.jsp?i=7380

Grueso-Hinestroza, M. y Antón-Rubio, M. (2011). Prácticas de conciliación entre la vida personal y laboral: Comparación entre muestras procedentes de España y Colombia. Investigación \& Desarrollo, 19(1), 42-63. https://www.redalyc.org/ articulo.oa?id $=268 / 26820752006$

Hernández, J. (2007). Toma de decisiones públicas desde las perspectivas del proceso tecnocrático y la participación ciudadana: caso venezolano. Revista Venezolana de Gerencia, 12(40), 553-571. https:/ / produccioncientificaluz.org/index.php/rvg/ article/view/10476

Ley 446 de 1998. (1998, 7 de julio). Congreso de la República de Colombia. Diario Oficial Nro. 43.335. http://www.secretariasenado.gov.co/senado/basedoc/ ley_0446_1998.html

Ley 270 de 1996. (1996, 15 de marzo). Congreso de la República de Colombia. Diario Oficial Nro. 42.745. http://www.secretariasenado.gov.co/senado/basedoc/ ley_0270_1996.html

Ley 640 de 2001. (2001, 5 de enero). Congreso de la República de Colombia. Diario Oficial Nro. 44.303. http://www.secretariasenado.gov.co/senado/basedoc/ ley_0640_2001.html

Ley 1564 de 2012. (2012, 12 de julio). Congreso de la República de Colombia. Diario Oficial Nro. 48.489. http://www.secretariasenado.gov.co/senado/basedoc/ ley_1564_2012.html

Maldonado, M. y Montaña, L. (2017). Arbitraje: mecanismo alternativo de solución de conflictos o privatización judicial. Jurídicas CUC, 13(1), 121-146. https:/ / doi.org/ 10.17981/juridcuc.13.1.2017.06

Meza, A., Arrieta, M. y Noli, S. (2018). Análisis de la conciliación extrajudicial civil en la Costa Atlántica colombiana Jurídicas CUC, 14(1), 187-210. https://doi.org/ 10.17981/juridcuc.14.1.2018.09 
Ministerio del Interior y de Justicia. (2004). Concepto Nro. 12919. Presidencia de la República de Colombia. https://www.redjurista.com/Documents/concepto_ 12919_de_2004_ministerio_del_interior_y_de_justicia.aspx

Mojica, F. (2015). Análisis de la estructura de las pretensiones y excepciones como elementos esenciales del proceso y de la sentencia judicial. Revista Republicana, (7). http://ojs.urepublicana.edu.co/index.php/revistarepublicana/article/view/ 100

Paz Russi, C. A. (2015). Estudio Doctrinal y Jurisprudencial del Proceso Civil, Bogotá, Editorial ECOE.

Peña-Sandoval, H. (2017). La conciliación no es Justicia. Pensamiento Jurídico, 0(45), 241-267. https:// revistas.unal.edu.co/index.php/peju/article/view/65676

Salazar, L. M. y Cabello-Tijerina, P. A. (2020). La conciliación en equidad. Herramienta para la construcción de paz en Colombia. Revista Jurídicas, 17(2), 283-299. https:// doi.org/10.17151/jurid.2020.17.2.15

Sentencia C-1195. (2001, 15 de noviembre). Corte Constitucional (Manuel José Cepeda Espinosa y Marco Gerardo Monroy Cabra, MP). https:/ / www.corteconstitucional. gov.co/relatoria/2001/c-1195-01.htm

Tamayo Lombana, A. (2004). Manual de Obligaciones. Sexta Edición, revisada y ampliada. Bogotá, Editorial Temis.

Tamez, G., Montalvo, D., Leyva, O. y Hernández, A. (2018). Análisis comparativo sobre los métodos alternativos para la resolución de conflictos a partir de la legislación de los Estados de la República Mexicana. Justicia, 24(34), 385-404. http:/ / dx.doi.org/10.17081/just.23.34.2899

Toscano López, F. (2015). Algunas facetas del derecho fundamental al acceso efectivo a la administración de justicia en Colombia. Revista De Derecho Privado, (29), 213232. https:// doi.org/10.18601/01234366.n29.09 
